\title{
Nilai-Nilai Edukatif dalam Karya Felix Y. Siauw
}

\author{
Setya Utami \\ MTs Darul Ma'arif Pringapus \\ Email: setyautami@gmail.com
}

\begin{abstract}
Abstrak
Penelitian ini bertujuan untuk menggali nilai-nilai pendidikan karya Felix Y. Siauw, yaitu How to Master Your Habits, Yuk Berhijab, Udah Putusin Aja, dan Beyond the Inspiration. Masalah dalam penelitian ini adalah apa saja nilai-nilai pendidikan yang terdapat dalam karya felix Y. Siauw. Penelitian merupakan penelitian kualitatif (library research) dengan pendekatan deskriptif. Analisis deskripsi bibliografi terdiri temuan fakta, hasil, dan gagasan pemikiran seseorang melalui bagaimana menemukan, menganalisis, menafsirkan. Hasil penelitian menunjukkan bahwa nilainilai pendidikan pada buku Felix Y. Siauw adalah: 1) nilai-nilai individu: visioner, termotivasi, serius, sabar, rajin, memaafkan, bergerak, mudah beradaptasi, tabayyun, kepemimpinan, kelincahan, mempelajari sebabsebab kemenangan, simpati, waspada, tidak terburu-buru, rasional, meluruskan niat, adil, optimis, amanah, tawadhu', jujur, husnudzan, rindu pada kebaikan, kecerdasan emosional, keberanian, tawakal, tegas, dan ketulusan; 2) nilai-nilai sosial: kesetaraan gender dalam Islam, adab berpakaian, jihad, kekompakan, pendidikan prenatal, menjunjung hak asasi manusia, birrul walidain, tata tertib, etika pergaulan dalam Islam, etika terhadap musuh, keteladanan, toleransi, serta adab makan dan
\end{abstract}


minum; 3) nilai-nilai praktis: langkah membentuk habits; 4) nilai-nilai dakwah: melembaga, menyampaikan kebaikan, dan kewajiban.

The purpose of this research is to explore the educational values in Felix Y. Siauw opus, i.e. How to Master Your Habits, Yuk Berhijab, Udah Putusin Aja, and Beyond the Inspiration. The problem in this research is what are the educational values in the books. It is a qualitative research (library research) with descriptive analysis. The analysis of the bibliographic description comprise finding of fact, the results, and the idea of a person's thinking through how to find, analyze, interpret. The results show that educational values on the books of Felix Y. Siauw are: 1) individual values: visionary, motivated, serious, patient, diligent, forgive, move, adaptable, tabayyun, leadership, agility, study the causes of victory, sympathy, alert, unhurried, rational, straightening intentions, fair, optimistic, trustworthy, tawadhu', honest, husnudzan, longing for goodness, emotional intelligence, courage, trust, firm, and sincerity; 2) social values: gender equality in Islam, manners on dressing, jihad, compactness, prenatal education, uphold human rights, birrul walidain, rules, etiquette in Islam, ethics against the enemy, exemplary, tolerance, as well as table manners and drink; 3) practical values: the step to form habits; 4) propaganda values: institutionalized, convey kindness and obligations.

Kata kunci: nilai-nilai edukatif, karya, Felix Y. Siauw

\section{Pendahuluan}

Keluaran pendidikan seharusnya dapat menghasilkan orang "pintar" dan "baik" dalam arti luas. Pendidikan tidak hanya menghasilkan orang "pintar" tetapi "tidak baik", sebaliknya juga pendidikan tidak hanya menghasilkan orang "baik" tetapi "tidak pintar" (Hidayatullah, 2010: 1).

Pendidikan dapat diperoleh tidak hanya melalui pendidikan formal tetapi juga informal dan nonformal. Dalam Islam, pendidikan 
senantiasa bersambung (kontinu) dan tanpa batas. Hal ini karena hakikat pendidikan Islam merupakan proses tanpa akhir sejalan dengan konsensus universal yang ditetapkan Allah SWT dan Rasul-Nya, dengan istilah life long education (Muhaimin, 1993: 138). Pentingnya pendidikan ditegaskan dalam Qs. al-'Alaq ayat 1-5: "Bacalah dengan (menyebut) nama Tuhanmu yang Menciptakan. Dia telah menciptakan manusia dari segumpal darah. Bacalah, dan Tuhanmulah yang Maha pemurah, yang mengajarkan manusia dari perantaraan kalam. Dia mengajar manusia apa yang tidak diketahuinya".

Pendidikan tidak hanya mau mengembangkan ilmu, ketrampilan, teknologi, tetapi juga ingin mengembangkan aspek-aspek lainnya: kepribadian, etik moral dan lain-lain, yang kesemuanya disebut pendidikan nilai (Kaswardi, 1993:3). Salah satu sumber belajar yang sangat vital adalah buku, dengan membaca buku kita dapat menggali nilai-nilai pendidikan.

Felix Y. Siauw adalah seorang Islamic Inspirator. Ustadz Felix dalam sapaan akrabnya adalah seorang mualaf yang dapat menjadi sosok ustadz dalam 10 tahun usia muslimnya. Beliau aktif mengisi kajian di perkantoran, pesantren, radio, dan masjid. Selain itu, beliau juga mengisi kajian yang ditayangkan beberapa stasiun televisi, baik nasional yaitu TVRI dalam acara Ispirasi Islam, maupun swasta yaitu TV One sebagai bintang tamu dalam acara Satu Jam Lebih Dekat dengan Felix Y. Siauw, Trans TV dalam acara Mozaik Islam, dan Channel TV dalam acara Inspiring Islam. Tidak hanya itu, Ustadz Felix juga mengisi Share kajian 
di luar negeri. Negara yang pernah mendatangkan Ustadz Felix antara lain: Australia, Jepang, dan Amerika.

Hal menarik dari beliau adalah sebutannya sebagai ustadz sosial media. Kiprah beliau dalam menyampaikan agama di jejaring sosial membuatnya terkenal di dunia maya. Dunia di mana penghuninya didominasi oleh remaja. Tulisan Ustadz Felix di facebook maupun di twitter kerap menggunakan diksi yang tepat, kata-kata Ustadz Felix yang sampai ke lubuk hati, dan tetap mudah dipahami. Analisis logis yang menggunakan fakta-fakta real dan tidak banyak berdalil, menjadikan tulisannya mudah diterima para remaja. Pemikiran nilai-nilai edukatif oleh Felix Y. Siauw terangkum dalam empat buku yaitu How to Master Your Habits, Yuk Berhijab, Udah Putusin Aja, dan Beyond The Inspiration. Mempertimbangkan sisi menarik dari buku-buku tersebut dalam perspektif pembelajar dan merosotnya nilai-nilai edukatif belakangan ini, maka kiranya penting bagi penulis untuk meneliti nilainilai edukatif dari buku tersebut guna berkaca untuk kebaikan generasi penerus yang akan datang.

\section{Metode Penelitian}

Penelitian ini merupakan penelitian kualitatif dengan pendekatan deskriptif. Jenis penelitian ini adalah penelitian kepustakaan (library research), dengan menggunakan pendekatan deskriptif analisis (descriptive of analyze research). Deskripsi analisis ini mengenai bibliografis. Penelitian ini mengunakan literatur dan teks sebagai objek analisis yaitu buku-buku yang kemudian dideskripsikan dengan cara 
menjelaskan teks-teks dalam buku-buku itu yang mengandung nilai-nilai edukatif kemudian memberikan pemahaman atas teks-teks yang dideskripsikan.

\section{Pembahasan}

\section{Biografi Felix Y. Siauw}

Felix Yanwar Siauw merupakan sosok pendakwah yang terkenal di sosial media terutama facebook dan twitter. FX Iwan S dengan Jarniwati Ishack mempunyai lima orang anak, salah satunya adalah Ustadz Felix. Ustadz Felix kelahiran Palembang, 31 Januari 1984. Berlatar belakang keluarga keturunan etnis Tionghoa. Dibesarkan dalam keluarga Katolik yang taat.

Kehidupan Ustadz Felix mulai berubah semenjak keraguannya di dalam agamanya. Membenci agama tetapi masih percaya pada Tuhan. Mulai mendalami Islam sejak masuk di bangku kuliah. Kemudian memutuskan masuk Islam pada tahun 2002. Meskipun Ustadz Felix sudah menjadi mualaf, Ustadz Felix tetap menjalin hubungan baik dengan kedua orang tuanya dan saudara-saudaranya yang kesemuanya berbeda agama.

Nilai-nilai edukatif karya Felix Y. Siauw terangkum dalam empat buku yaitu How to Master Your Habits, Yuk Berhijab, Udah Putusin Aja, dan Beyond The Inspiration.

\section{Buku How to Master Your Habits}

Buku ini terdiri dari 169 halaman yang berisi bagaimana cara mengusai keahlian tanpa motivasi, bahkan tanpa berpikir. Buku ini juga 
dikhususkan untuk para pejuang dakwah Islam. Buku ini akan menuntun bagaimana pekerjaan bisa dilakukan secara otomatis, mendakwahkan Islam, beribadah pada Allah, dan juga melakukan kebaikan secara otomatis.

Menurut Ustadz Felix, motivasi saja ternyata tidak cukup untuk membuat seseorang memiliki keahlian-keahlian yang diperlukan dalam berdakwah (Siauw, 2014d: iv). Tulisan yang dibuat Ustadz Felix pada buku ini terinspirasi dari kawan-kawannya yaitu seorang pengemban dakwah bukan pustakawan yang kecanduan buku-buku sejarah dan referensi Islam lainnya kemudian mampu menceritakannya kembali, Ustadz Felix juga mengenal pengemban dakwah bukan wartawan namun mampu menghasilkan tulisan dakwahnya sama cepatnya dengan dokter menuliskan resep untuk pasien, ada juga pengemban dakwah yang bukan arabian namun mampu membaca literatur Arab gundul sama cepatnya dengan anak SMA membaca komik, selain itu ada pengemban dakwah yang terlahir jauh dari hartawan namun mampu membantu orang-orang kesulitan sama ringannya dengan kapas. Ustadz Felix berharap agar buku ini bukan hanya menginspirasi tapi juga agar mampu mengkondisikan setiap pengemban dakwah untuk menguasai keahlian di jalan dakwah.

Dalam buku ini penulisan tidak disajikan daftar isi. Bagian awal dimulai dengan Greet Them 'The Inspirator yang isinya mengajak pembaca untuk menengok orang-orang hebat di dalam Islam yaitu Imam Syafi'i yang mampu menghafal al-Qur'an pada usia tujuh tahun dan hafal kitab al-Muwaththa' pada usia dua belas tahun. Ath-Thabari setiap hari menulis empat puluh lembar dalam 40 tahun hidupnya. Khalid bin Walid 
ahli dalam bidang militer yang mampu memporak-porandakan Persia dan Romawi dalam beberapa tahun. Siti Aisyah penghafal hadis terbanyak dari kalangan sahabiyyah. Serta keteladanan pada sifat kedermawanan Abdurrahman bin Auf. Sayangnya kebanyakan orang Islam hanya berhenti di rasa kagum dan menganggap kelebihan yang dimiliki seseorang adalah takdir Allah. Padahal kenyataannya bertolak belakang dari anggapan seperti itu. Namun, keahlian adalah hasil pilihan, latihan, dan pengulangan pilihan-pilihan yang telah dibuat.

Tulisan-tulisan berikutnya Ustadz Felix menyatakan bahwa bukan bakat yang lebih berpengaruh dalam keahlian (atau ketidak ahlian) seseorang, melainkan sesuatu yang lain yaitu habits (kebiasaan). Dengan kata lain seseorang yang sukses dalam mengemban dakwah memiliki 'habits sukses pengemban dakwah' dan habits inilah yang bertanggung jawab terhadap kebaikan-kebaikan yang muncul. Sebaliknya habits juga bertanggung jawab atas buruknya kehidupan seseorang (Siauw, 2014d: $6)$.

Pada judul Everything are Habits diterangkan habits adalah segala sesuatu yang kita lakukan secara otomatis, bahkan kita melakukannya tanpa berfikir. Habits adalah suatu aktivitas yang dilakukan secara terus menerus sehingga menjadi bagian dari seseorang. Dia adalah kebiasaan kita. Jadi menguasai bahasa adalah habits, rajin dan malas pun juga habits, kreatif dan jumud juga habits, ramah dan pemarah juga habits, bahkan kaya dan miskin juga hasil dari habits, sampai bersemangat dakwah juga futur adalah hasil habits (Siauw, 2014d: 21). Diri kita mempunyai program-program yang mengatur semua respons 
kita, dan semua itu adalah habits. Semua tergantung habits, sehingga seorang muslim akan berpikir dengan jalan yang berbeda dengan nonmuslim. Sumber pemikiran muslim berasal dari habits taat pada Allah.

Habits adalah penentu nilai pribadi kita. Habits adalah pembentuk kepribadian kita di mata orang lain, yang membuat kita berharga di hadapan orang lain. Seseorang yang memiliki banyak habits baik dalam dirinya sudah dapat dipastikan akan lebih berhasil dalam kehidupannya dibandingkan dengan seseorang yang memiliki sedikit habits yang baik (Siauw, 2014d: 29). Proses terbentuknya habits: thoughts, purposes, action, habits, dan person abilities.

Pemikiran adalah pangkal daripada kepribadian, karena pemikiranlah yang akan menentukan keyakinan, kecenderungan, tujuan hidup, cara hidup, pandangan hidup, sampai aktivitas seorang manusia. Pemikiran mendasar pada seorang manusia akan menghasilkan cara pandang khas ini, dalam terminologi Islam disebut dengan aqidah (Siauw, 2014d: 30).

Faktor yang menentukan habits adalah latihan dan pengulangan. Dalam al-Qur'an dijelaskan: "Dan demikianlah Kami menurunkan AlQur'an dalam bahasa Arab, dan Kami telah menerangkan dengan berulang kali di dalamnya sebahagian dari ancaman, agar mereka bertakwa atau (agar) al-Qur'an itu menimbulkan pengajaran bagi mereka” (Qs. Thahaa: 113). Dalam hadis Rasullullah SAW bersabda: "Sesungguhnya amalan yang paling disukai Allah yaitu yang dikerjakan terus menerus.” (HR. Bukhori Muslim) (Siauw, 2014d: 80). Membentuk habits memerlukan kejelasan tujuan, maka sering-seringlah berpikir 
tentang masa depan, merencanakan masa depan. Karena masa depan menentukan aktivitas apa yang akan kita lakukan pada saat ini (Siauw, 2014d: 57).

Untuk membentuk habits kita tidak perlu merasa berubah ataupun memiliki motivasi karena dalam banyak kasus habits bisa terbentuk walaupun seseorang tidak memiliki motivasi sama sekali. Habits bisa terbentuk baik ketika kita rela dengan repetisi aktivitas itu ataukah kita terpaksa melakukannya. Rela ataupun terpaksa, habits akan tetap terbentuk, walaupun habits yang dibentuk atas dasar kerelaan tetap akan lebih berkualitas dibandingkan dengan habits yang terbentuk karena paksaan. Perlu diketahui bahwa mengendalikan habits adalah sebuah pilihan.

Ciptakan keberuntungan dengan habits jangan menunggu keberuntungan (Siauw, 2014d: 94). Seorang pengemban dakwah yang selalu meluaskan pengetahuannya dengan membaca buku, melatih dirinya untuk menulis, berdakwah dengan bersemangat, beribadah dengan khusyuk dan menaati Allah semaksimal mungkin, maka dipastikan dia akan lebih beruntung dalam karir dakwahnya dibandingkan dengan pengemban dakwah yang tidak melakukannya. Keberuntungan adalah hasil kali dari persiapan dan kesempatan.

Langkah praktis dan mudah untuk membentuk habits baru: 1) mulai dari yang kecil (mematok target yang tinggi hanya akan menghasilkan rasa jenuh dan putus di tengah-tengah, misalnya: ingin membenuk habits membaca buku, memulai dengan 10 menit sehari, apabila telah terbiasa target akan meningkat secara otomatis); 2) temukan 
tempat habits (menyisipkan habits baru pada habits yang sudah jadi, kuncinya adalah kata 'setelah', misalnya: saya akan menbaca setelah shalat subuh); 3) berlatihlah terus (menempel pengingat, meminta teman untuk mengingatkan, dan ingat untuk melakukan setiap hari).

Seorang muslim tidak akan merasa puas dengan hanya membentuk habits. Namun ia harus dikembangkan menjadi expertise (keahlian spesialis). Seorang expert mampu memberikan manfaat tidak hanya bagi dirinya sendiri namun juga bagi orang lain (Siauw, 2014d: 102). Seorang expert menjadikan dirinya sendiri sebagai role model, dan bisa menduplikasi keahlian yang sama pada orang lain, berbagi keahlian. Perlu waktu untuk bisa melakukan sesuatu dengan benar, dan perlu banyak waktu untuk menjadikannya habits, dan lebih banyak waktu untuk menjadikannya expert, dan mungkin perlu waktu seumur hidup untuk menjadikannya master. Tidak ada jalan pintas untuk dapat menguasai suatu keahlian. Perlu kesabaran untuk terus melakukan habits yang ingin kita bentuk (Siauw, 2014d: 109).

Gerakan dakwah ibarat tubuh manusia, tidak ada satu bagian yang lebih penting dari bagan yang lain, masing-masing mempunyai fungsi khusus. Dalam gerakan dakwah, setiap bagian mempunyai kontribusi masing-masing. Karena itu, Rasulullah mencontohkan dakwah mesti berjamaah (Siauw, 2014d: 111). Maka yang membuat kita berharga dalam dakwah adalah ketika kita memiliki kelebihan yang signifikan dalam satu keahlian dakwah. Menjadi ahli dalam satu bidang bukanlah kesombongan, karena sombong itu sendiri adalah menolak kebenaran dan meremehkan manusia (Siauw, 2014d: 113). 
Action adalah pertanda kesungguhan, ia pembeda antara impian dan khayalan. Juga pembeda antara orang munafik dan orang beriman (Siauw, 2014d: 133). Kemudian visioner dijadikan suatu sikap mental wajib bagi para pengemban dakwah. Meyakini visi yang diberikan oleh Allah dan Rasul-Nya, serta berjuang sekuat tenaga karenanya tidak akan dapat dilakukan maksimal apabila kita tidak visioner (Siauw, 2014d: 142). Bagi seorang pengemban dakwah yang visioner, kenyataan terpuruknya kaum muslim di zaman ini tidak menjadikan ia yakin bahwa Islam tak akan bangkit kembali, sebaliknya ia justru semakin yakin bahwa kondisi ini akan dibalik oleh Allah.

Buku ini diakhiri dengan epilog yang berkesimpulan, semua orang memiliki keterbatasan dan masalah masing-masing. Semua orang bisa saja mencari alasan untuk gagal, sama seperti dia bisa mencari alasan untuk berhasil (Siauw, 2014d: 168). Semua adalah pilihan kita. Alasan untuk gagal atau alasan untuk sukses, keduanya memerlukan waktu dan juga menguras pikiran.

\section{Buku Yuk Berhijab}

Buku ini merupakan sebuah buku yang memotivasi muslimah untuk berhijab, dan bagi muslimah yang sudah berhijab untuk menyempurnakan hijabnya agar sesuai dengan syariat Islam. Buku setebal 148 halaman dengan sampul merah muda dan penuh gambar ilustrasi membuat pembaca tidak mudah bosan dibandingkan dengan membaca buku yang bertuliskan hitam dan dengan latar belakang putih. 
Di dalam buku Yuk Berhijab disajikan sembilan bab yaitu: Dunia Memandang Wanita, Pandangan Islam tentang Wanita, Wanita dan Aurat, Menutup Aurat dan Pakaian Syar'i Penutup Aurat, Berpakaian tetapi Telanjang, Tabarruj, Hijab Bukan Perhiasan, Kata Orang, Berhijablah dan Taatlah. Dalam setiap bab disajikan catatan si benefiko yaitu seorang muslimah yang bernama asli Emeralda Noor Achni, dipanggil benefiko karena di akun twitter-nya lebih dikenal dengan @BENEFIKO. Catatan si benefiko berisi cerita dalam bentuk komik mengenai perjalanan berhijab seorang muslimah.

Isi dari bab satu yang berjudul Dunia Memandang Wanita diawali dengan pandangan berbagai peradaban tentang wanita. Peradaban Yunani kuno membolehkan wanita diperjual belikan layaknya budak, tidak memiliki hak sipil dan juga hak waris (Siauw, 2015b: 12). Pandangan Romawi pada wanita dapat dilihat dari kisah perselingkuhan para dewa yang menghiasi mitologi Romawi. Kisah selingkuh, hubungan di luar nikah, membentuk pandangan Romawi kuno tentang siapa wanita. Bagi mereka, wanita hanya objek seksual untuk dinikmati, bukan dikasihi (Siauw, 2015b: 15). Di India yang menganut tradisi Hindu mengenal istilah sati sebuah prosesi membakar diri bagi janda yang ditinggal mati suaminya. Saat suaminya meninggal dan dibakar, berakhirlah hak hidupnya sebagai bagian dari loyalitas. Peradaban Cina Kuno wanita ditempatkan sebagai warga kelas dua. Anggapan wajar bahwa wanita hanya diciptakan untuk melayani lelaki. Belajar dan menjadi cendikiawan hanya hak lelaki. Mungkin di antara peradaban yang dahulu dikenal dunia, hanya wanita Mesir berstatus bangsawan, yang sedikit 
menghirup hak sebagai manusia, setidaknya mereka mengenal Hatshepsut dan Cleopatra sebagai wanita yang memegang tengkuk kekuasaan.

Setelah membandingkan berbagai peradaban, di buku Yuk Berhijab kemudian membandingkan berbagai agama. Telah disepakati bahwa agama diturunkan untuk kebaikan (Siauw, 2015b: 16). Kebaikan tidak dikhususkan bagi kaum pria semata, namun juga bagi kaum wanita. Tapi, sejarah mancatat sebaliknya. Tafsir dari teks-teks kitab suci dan pendapat-pendapat agamawan pada agama Yahudi dan Nasrani justru berujung pada diskriminasi wanita. Contoh dalam Talmud, Menahoth 43b-44a tertulis bahwa, "Seorang lelaki Yahudi diwajibkan membaca doa berikut setiap hari: 'Terima kasih Tuhan! Karena tidak menjadikanku seorang kafir, seorang wanita, atau budak belian' (Siauw, 2015b: 17). Dalam toelogi nasrani, wanita dianggap bertanggung jawab atas diusirnya Adam dari surga. Karena wanita termakan rayuan setan. "Lagi pula bukan Adam yang tertipu, melainkan perempuan itulah yang tertipu dan jatuh ke dalam dosa." (Timotius 2: 214) (Siauw, 2015b: 19). Saat Islam bersentuhan dengan budaya Eropa, pemikiran tentang hak asasi manusia mulai bangkit. Dan kaum wanita menuntut kesetaraan yang tidak diberikan oleh agama dan negara.

Emansipasi kemudian muncul, kesetaraan gender digelar, bendera feminisme dikibarkan (Siauw, 2015b: 20). Di antara kaum wanita mulai bangkit dan menuntut kesetaraan antara lelaki dan wanita. Perjuangan bukannya berakhir pada hasil yang memuliakan wanita, tetapi berujung pada penghancuran martabat, karena mengingkari fitrah. Bila pada masa 
lalu wanita direndahkan secara terpaksa, saat ini wanita rela untuk direndahkan. Menghinakan diri demi sekeping emas dengan badan sebagai modal. Pada masa kini hiburan, pertunjukan, iklan, fashion, dan seni menjadi alasan untuk menanggalkan harga diri, atas nama tren, wanita-wanita berlaku tanpa rasa malu. Ketika agama berganti dengan sekularisme yang menjadikan standar kebahagiaan dan kesuksesan adalah dunia. Eksploitasi tubuh wanita menjadi bisnis dan wanita itu sendiri menjadi bangga terhadap apa yang dipamerkannya. Saat itulah tiada lagi kehormatan (pelacuran visual).

Pada bab dua yang berjudul Pandangan Islam tentang Wanita, berisi Islam memandang bahwa kebahagiaan manusia bukan terletak pada harta, tahta, dan cinta semata, tatapi terletak pada ridho Allah. Karenanya, baik lelaki maupun wanita punya kesempatan yang sama untuk meraihnya (Siauw, 2015b: 34). Lelaki dan wanita tidak berkompetisi di jalur yang sama, tetapi berkompetisi di jalur kebaikan yang berbeda. Karena lelaki dan wanita memang berbeda.

Dalam timbangan syariat Islam, bila lelaki memperoleh kemuliaan dengan bekerja, wanita mendapatkannya dengan mengurus rumah tangga. Saat lelaki diberikan pahala oleh Allah dengan memperebutkan shalat di shaf terdepan, wanita mendapat pahala yang sama dengan shaf paling belakang. Jika lelaki memperoleh pahala tertinggi dengan jihad fi sabilillah, wanita memperoleh pahala semisal dari melahirkan anak-anaknya, atau melaksanakan umrah dan haji. Islam memberi jalur beribadah kepada wanita, dengan kelebihan-kelebihan yang Allah berikan untuk wanita, bukan beradu dengan lelaki yang Allah 
beri kelebihan yang berbeda. Konsekuensinya Islam juga memberikan hukum yang berbeda kepada lelaki dan wanita dalam rangka beribadah kepada Allah. Karena itulah, lelaki dan wanita sama di hadapan Allah.

Pada masa Arab Jahiliyah, keberadaan keturunan perempuan dianggap sebagai aib karenanya tidak jarang bayi perempuan dikubur hidup-hidup. Kemudian Islam datang dengan pencerahan. Al-Qur'an turun dengan nasihat sebagaimana firman Allah pada Qs. al-Hujurat ayat 13, yang artinya: "Wahai manusia, sesungguhnya Kami menciptakan kamu dari seorang laki-laki dan seorang perempuan dan menjadikan kamu berbangsa-bangsa dan bersuku-suku supaya kamu saling mengenal. Sesungguhnya orang yang paling mulia di sisi Allah ialah orang yang paling bertakwa. Sesungguhnya Allah Maha Mengetahui lagi Maha Mengenal”. Islam juga memuliakan wanita sebagaimana sabda Rasulullah SAW: "Menuntut ilmu itu adalah wajib atas seluruh kaum muslim dan muslimat” (HR. Muslim). Demikianlah Islam menyamakan hak pendidikan bagi muslim laki-laki dan perempuan.

Saat menikah, Islam memberi peran sentral kepada wanita dalam urusan rumah tangga. Bila Islam menjadikan lelaki sebagai pemimpin keluarga, Islam menjadikan wanita sebagai pemimpin bagi rumahnya. Walau lelaki dilebihkan Allah untuk memimpin wanita, bukan berarti lelaki dibolehkan bertindak semena-mena. Sirah nabawiyah menjadi teladan bagi orang Islam.

Islam tidak hanya berbicara dalam tataran konseptual. Namun mengatur masalah teknis dalam memulikan wanita, dari urusan pendidikan sampai tataran pernikahan, dari masalah keluarga sampai 
warisan, dari pakaian sampai perhiasan (Siauw, 2015b: 44). Pada bab selanjutnya dibahas khusus bagaimana Islam memuliakan wanita dari aturan berpakaian. Bagaimana Islam memuliakan wanita dengan menutup aurat. Bagaimana wanita dihormati dengan hijab.

Bab tiga berjudul Wanita dan aurat membahas tentang Islam mewajibkan jilbab dan kerudung, bukan bermaksud memasung namun agar wanita terhormat dan terlindung. Secara makna syariat, aurat adalah bagian tubuh yang haram dilihat, dan karena itu harus ditutup. Khusus bagi muslimah, auratnya adalah semua bagian tubuhnya, kecuali wajah dan telapak tangan.

Bab empat berjudul Menutup Aurat dan Pakaian Syar'i Penutup Aurat. Islam adalah agama yang unik dan memuliakan wanita, Islam telah membagi dua kehidupan, yaitu kehidupan umum (hayatul 'am) dan kahidupan khusus (hayatul khash). Dikatakan kehidupan khusus, yaitu bila seseorang harus meminta izin untuk masuk ke dalamnya. Dan dikatakan kehidupan umum apabila seseorang tidak memerlukan izin untuk berada di dalamnya. Sebagaimana firman Allah: "Hai orang-orang yang beriman, janganlah kamu memasuki rumah yang bukan rumahmu sebelum meminta izin dan memberi salam kepada penghuninya. Yang demikian itu lebih baik bagimu, agar kamu (selalu) ingat” (Qs. al-Nur: 27).

Pakaian wanita di kehidupan khusus saat berada di rumahnya, dalam melakukan aktivitas-aktivitas yang biasa dia lakukan bersama dengan mahram-nya, tentu wanita muslimah tidak perlu menutup aurat dengan pakaian lengkapnya sebagaimana keluar rumah. Karena Allah 
membolehkan mahram wanita muslimah itu untuk meliat bagian tubuh wanita sampai batas tempat melekat perhiasannya. Sebagaimana firman Allah: “ ...Dan janganlah menampakkan periasannya (auratnya), kecuali kepada suami mereka, atau ayah mereka, atau ayah suami mereka, atau putra-putra mereka, atau putra-putra suami mereka, atau saudarasaudara laki-laki mereka, atau putra-pura saudara laki-laki mereka, atau putra-putra saudara perempuan mereka, atau perempuanperempuan Islam, atau budak-budak yang mereka miliki, atau pelayan laki-laki (tua) yang tidak mempunyai keinginan (terhadap perempuan), atau anak-anak yang belum mengerti tentang aurat perempuan" (Qs. alNur: 31). Maksud dari perhiasan dalam ayat tersebut menurut para ulama adalah tempat melekatnya perhiasan, seperti leher, pergelangan tangan, ataupun pergelangan kaki. Mahram boleh melihat sesuatu yang biasa tampak dari aurat seorang wanita, seperti anggota-anggota wadhunya.

Adapun bila wanita berada di rumah mereka, dan di sana terdapat laki-laki asing (non-mahram) yang memungkinkan lelaki itu memandangnya, wanita muslimah wajib mengenakan pakaian yang menutup semua aurat (al-tsaub), ditambah dengan kain kerudung (khimar) yang menutupi kepala hingga batas dada. Sebagaimana firman Allah: "Katakanlah kepada perempuan yang beriman, hendaklah mereka menahan pandangannya, dan memelihara kemaluannya, dan janganlah mereka menampakkan perhiasannya (auratnya), kecuali yang (biasa) tampak daripadanya. Dan hendaklah mereka menutupkan kain kerudung hingga batas dadanya ... " (Qs. al-Nur: 31). 
Selain beraktivitas di kehidupan khusus, tentu wanita tidak bisa menghindarkan dirinya untuk beraktivitas di kehidupan umum atau di tempat-tempat umum ketika dia bertemu dengan lelaki asing (nonmahram). Pada kehidupan umum inilah wanita disyariatkan mengenakan pakaiantambahan untuk menutup auratnya, yaitu jilbab. Perinta Allah untuk mengenakan jilbab yaitu: "Hai Nabi! Katakanlah kepada istriistrimu, anak-anak perempuanmu, dan istri-istri kaum mukmin, hendaklah mereka mengulurkan jilbabnya ke seluruh tubuh mereka, yang demikian itu supaya merekalebih mudah untuk dikenal, karena itu mereka tidak diganggu. Dan Allah adalah Maha Pengampun lagi Maha Penyayang” (Qs. al-Ahzab: 59).

Ulama berbeda pendapat dalam mengartikan jilbab, ada yang mengartikan jilbab itu khimar (yang menutupi kepala, leher, hingga batas dada). Ada yang mengartikan jilbab adalah miqna'ah (kain yang menutup kepala dan muka). Ada yang mengartikan milhafah (mantel). Ada pula izar (baju layaknya selimut yang menyelubungi badan). Ada pula mula'ah (baju kurung yang memiliki lengan).

Bab lima berjudul Berpakaian tetapi Telanjang. Rasul bersabda: "Ada dua golongan dari penduduk neraka yang belum pernah aku lihat, yaitu suatu kaum yang memiliki cambuk seperti ekor sapi untuk memukul manusia dan para wanita yang berpakaian tetapi telanjang, berlenggaklenggok, kepala mereka seperti punuk unta yang miring. Wanita seperi itu tidak akan masuk surga dan tidak akan mencium baunya, walaupun baunya tercium selama perjalanan sekian dan sekian” (HR. Muslim) (Siauw, 2015b: 90). Dan satu hadis yang berbunyi: “ ... wanita-wanita 
yang berpakaian tetapi telanjang, yang berjalan berlenggak-lenggok guna membuat manusia memandangnya, mereka tidak akan masuk surga dan tidak mencium aromanya. Padalah aroma surga bisa dicium dari jarak 500 tahun ...” (HR. Imam Malik) (Siauw, 2015b:91). Pengertian berpakaian tetapi telanjang menurut Imam An-Nawawi ada yang bermakna hakiki dan makna esensi. Semuanya adalah benar dan harus dihindari oleh muslimah yang ingin taat kepada Allah (Siauw, 2015b: 92). Ulama menyepakati maksud berpakaian tetapi telanjang adalah memakai pakaian tipis, atau menyingkap sebagian aurat. Sedangkan kata berlenggak-lenggok di dalam hadis itu adalah wanita yang tidak menjaga kehormatan dan kemaluan mereka, yaitu dengan berjalan menggoyangkan pundak mereka hingga diperhatikan lelaki. Mereka cenderung suka dengan perhatian lelaki ataupun yang tingkahnya ditujukan untuk menggoda lelaki (Siauw, 2014a: 93).

Bab enam berjudul Tabarruj. Allah berfirman dalam Qs. al-Nur ayat 31 “... hendaklah mereka menahan pandangannya dan memelihara kemaluannya, dan janganlah mereka menampakkan perhiasannya ...”. Perintah ini berlaku tidak hanya bagi wanita Islam tetapi juga untuk lakilaki Islam, artinya sama-sama menjaga. Karenanya seorang muslimah dilarang mendandani diri dengan pakaian ataupun berhias dengan sesuatu yang dapat menarik perhatian laki-laki. Syariat menyebut perilaku semisal dengan nama tabarruj (berhias yang berlebihan). Allah berfirman: "dan janganlah kamu bertabarruj dengan tabarruj jahiliyyah terdahulu” (Qs. al-Ahzab: 33). Tabarruj bisa terjadi dengan dandanan wajah, bisa pula dengan menggunakan parfum, atau mengenakan pakaian 
yang bercorak mentereng, bertingkah genit, dan menggoda lelaki dengan ucapan ataupun gaya jalan, atau menggunakan hijab yang tidak sempurna semisal ketat, transparan, atau menyingkap sebagian aurat yang harusnya tertutup (Siauw, 2015b: 104).

Indikasi kebolehan membuka jilbab bagi wanita tua yang sudah menopause yaitu firman Allah: "Dan perempuan-perempuan tua yang telah terhenti (dari haid dan mengandung) yang tiada ingin nikah (lagi), tiadalah atas mereka dosa meninggalkan pakaian luar (jilbab) mereka dengan tidak (bermaksud) bertabarruj. Dan berlaku sopan adalah lebih baik bagi mereka. Dan Allah Maha Mendengar lagi Maha Mengetahui." (Qs. al-Nur: 60).

Bab tujuh berjudul Hijab Bukan Periasan. Hijab adalah identitas wanita muslimah. Hijab ditujukan untuk menutupi perhiasan wanita dan melindungi keindahannya, bukan justru menjadi perhiasan baru atau pengganti keidahan. Karenanya, kerudung bukanlah pengganti keindahan rambut hingga dibentuk menyerupai rambut, bahkan untuk mendapat perhatian yang lebih dari sekedar rambut. Jilbab bukan pengganti kemolekan tubuh, yang ketat lalu menunjukkan lekuk badan. Rasulullah bersabda: "Siapa yang mengenakan pakaian popularitas (syuhrah) di dunia, maka Allah akan kenakan pakaian kehinaan kepadanya pada hari kiamat” (HR. Ahmad) (Siauw, 2015b: 115). Jadi hakikat jilbab adalah melindungi keindahan wanita hingga ia tidak menjadi perhatian lelaki. Karena wanita terlalu berharga untuk menjadi bahan perhatian semata (Siauw, 2015b: 118). 
Bab delapan berjudul Kata Orang, berisi motivasi untuk mengabaikan komentar miring tentang wanita berhijab. Sudah sewajarnya seseorang mencari teman dalam kesalahan dan biasanya yang menjadi kompor bagi muslimah untuk menanggalkan hijabnya adalah meraka yang tidak berhijab. Kasarannya ingin mendapat teman sebanyak-banyaknya dalam bermaksiat, hingga seolah-olah apa yang dilakukan dianggap benar karena banyak pendukungnya. Kemudian diingatkan pada suatu hadis: "Dari Abu Hurairah radiyallahu 'anhu bahwa Rasulullah shalallahu 'alaihi wasallam bersabda: Barangsiapa yang mengajak kepada suatu petunjuk, maka dia mendapat pahala seperti pahala orang yang mengikutinya, tanpa mengurangi sedikit pun dari pahala-pahala mereka. Dan barang siapa yang mengjak pada suatu kesesatan maka dia memperoleh dosa semisal dosa orang yang mengikutinya tanpa mengurangi sedikitpun dosa-dosa mereka” (HR. Muslim) (Siauw, 2015b: 135).

Bab sembilan berjudul Berhijablah dan Taatlah. Disampaikan bahwa hijab bukanlah pernyataan 'aku sudah baik' atau 'aku tiada dosa'. Hijab sederhananya pernyataan 'aku ingin taat' (Siauw, 2015b: 140). Hijab adalah usaha muslimah untuk menjauhi maksiat. Hijab memberikan sebuah pengingat bagi diri untuk senantiasa menjauhi dosa. Bahkan berhijab itu sendiri sudah menghindarkan diri dari dosa mengumbar aurat.

\section{Buku Udah Putusin Aja}

Buku dengan tebal 180 halaman adalah buku yang bermuatan dakwah, disajikan beberapa bab yang mengupas tentang maksiat pacaran 
di dalam Islam, bagaimana menghindarinya, dan bagaimana move on bagi yang telah menyudahi maksiat. Buku Udah Putusin Aja terdiri dari sebelas poin yaitu: cinta itu fitrah; salahkah merasa?; pacaran tanda dewasa atau beradegan dewasa?; pacaran dalam pandangan Islam; udah putusin aja; bagi yang sudah siap; khitbah-ta'aruf bagi yang sudah siap; bagi yang belum siap; udah putus, galau nih! Gimana bisa move on?; yang muda yang bercinta; kapan aku menikah?

Cinta adalah pemberian Allah dan karunia-Nya. Allah menanamkan rasa cinta pada jiwa sebagai bentuk dari rasa cinta-Nya agar manusia berfikir tentang-Nya. Allah yang menjadikan rasa cinta antara jenis yang berlawanan, sama seperti Allah jadikan rasa cinta manusia terhadap apapun yang diinginkan di dunia. Cinta bagi manusia adalah bagian dari fitrah, bagian dari naluri-naluri, al-Ghara'iz. AlGhara'iz adalah naluri-naluri yang tidak dapat diindra mata, namun terdapat pada manusia dan ia menuntut pemenuhan. Maka wajar saat seseorang sudah balig, ia mulai merasakan naluri ini. Bukan sebagai tanda yang salah, namun sebagai indikasi bahwa ia sudah siap melanjutkan keturunan. Bila cinta adalah karunia Allah, mustahil Allah mengaruniakan sesuatu yang buruk. Cinta bisa dimaknai sebagai potensi maksiat, juga bisa dimaknai sebagai potensi taat. Makna cinta itu luas, maka jangan disempitkan dengan syahwat. Islam adalah agama yang mengajarkan cinta kasih. Islam tidak pernah mengharamkan cinta, Islam mengarahkan cinta agar ia berjalan pada koridor yang semestinya. Islam mengatur bagaimana menunaikan cinta kepada orang tua, cinta kepada 
saudara seiman, kepada sesama manusia, juga tentu cinta kepada lawan jenis.

Bila berbicara cinta antara lawan jenis, satu-satunya jalan adalah pernikahan yang dengan semuanya cinta jadi halal dan penuh berkah (Siauw, 2013: 23). Islam melarang bentuk interaksi cinta yang tidak halal. Karena, Islam adalah agama yang memuliakan manusia dan mencegah kerusakan-kerusakan yang dapat terjadi pada manusia itu sendiri. Aturan Islam sederhana, bila cinta datangi walinya dan menikahlah, bila belum siap perisapkan diri terlebih dahulu. Islam tidak mengenal hubungan pra-pernikahan semisal pacaran dan pertunangan (Siauw, 2013: 30).

Kebanyakan muslim, khususnya remaja, beranggapan bahwa pacaran adalah tanda kedewasaan. Alasan berkenalan sebelum menikah adalah klise. Bukan pacaran namanya jika tidak berpegangan, berciuman, meraba-raba, atau segala perbuatan lain yang meninggikan syahwat. Tidak diragukan lagi bahwa pacaran adalah jalan bebas hambatan menuju zina dan ini hal yang sangat memprihatinkan (Siauw, 2013: 33). Disajikan data dari Komisi Perlindungan Anak Indonesia yang melakukan penelitian di 12 kota besar di Indonesia pada tahun 2007: 92\% pelajar melakukan kissing, petting, dan oral sex; 62\% pernah melakukan hubungan intim; 22,7\% siswi SMA pernah melakukan aborsi (Siauw, 2013: 34). Bila melihat fakta ini, seharusnya wanita sadar bahwa pacaran bukanlah aktivitas yang aman baginya dan bagi masa depannya.

Pacaran dalam pandangan Islam, Islam memandang lelaki dan wanita sama dalam penciptaan dan kemuliaannya, namun berbeda dalam 
hal fungsi dan penempatannya. Islam memberikan porsi khusus kepada wanita yang tidak diberikan kepada lelaki, begitupun sebaliknya. Karena itulah, aktivitas lelaki dan wanita dibedakan. Dalam kehidupan Islam sebagaimana yang dapat dibaca dalam sejarah Rasulullah atau buku-buku yang dapat menggambarkan kehidupan pada masa Rasulullah, aktivitas kaum lelaki dan wanita terpisah, kecuali dalam aktivitas khusus yang diperbolehkan syariat (jual beli, belajar mengajar, ibadah semisal haji dan umrah, berjihad di jalan Allah, dan segala aktivitas syar' $i$ yang menuntut adanya interaksi). Selain itu, wanita harus menutup aurat di hadapan lelaki bukan mahram-nya, menundukkan pandangan, menjaga kehormatan dan kemuliaan di hadapan lelaki. Tidak melakukan tabarruj yang dapat menggoda lelaki. Islam juga mewajibkan wanita bepergian dengan mahram, tidak melakukan perbuatan-perbuatan yang mengundang fitnah bagi dirinya semisal berkhalwat. Islam juga memberikan batasan bagi muslim secara umum untuk meminta izin dan memberikan salam sebelum memasuki rumah yang bukan rumahnya. Sehingga wanita di dalam rumah yang tidak menutup aurat bisa mempersiapkan diri sebelum menerima tamu (Siauw, 2013: 41). Dalam shalat lelaki diperintahkan oleh Rasulullah untuk melakukannya secara berjamaah di masjid, tidak diperintahkan bagi wanita walau boleh saja mereka ikut berjamaah di masjid. Saat melakukan shalat Rasulullah memisahkan barisan antara lelaki di depan dan wanita di belakang.

Pemisahan ini bukan ditujukan untuk mengekang dan menyusahkan, tetapi menjaga kehormatan dan kemuliaan wanita itu sendiri, menjaga masa depannya agar penuh dengan kebaikan (Siauw, 
2013: 42). Karena, Islam adalah agama preventif, Allah melarang keras untuk mendekati zina, apalagi melakukannya. Maka Islam menutup jalan untuk menuju perzinaan. Islam mengharamkan aktivitas interaksi antara lelaki dan wanita yang tidak berkepantingan syar'i seperti jalan-jalan bersama, pergi ke masjid atau kajian Islam, bertamasya, nonton bioskop, dan sebagainya. Aktivitas ini adalah pintu menuju kemaksiatan yang lain (Siauw, 2013: 44). Rasulullah bersabda: "Barang siapa beriman kepada Allah dan hari akhir, maka janganlah ia berkhalwat dia dengan seorang wanita tanpa ada mahram wanita tersebut karena setan menjadi yang ketiga di antara mereka berdua" (HR. Ahmad) (Siauw, 2013: 45).

\section{Buku Beyond The Inspiration}

Buku setebal 267 halaman yang mengingatkan suatu masa di mana Islam diingat sebagi suatu peradaban yang terbesar dan terhebat, memberikan kontribusi yang tak terhitung banyaknya dalam bidang sains dan kesejahteraan umat manusia. Islam kala itu diingat bukan hanya sebagai agama, tapi inspirasi agung bagi umatnya dalam menorehkan catatan sejarah dunia dengan tinta emas. Namun pada saat ini, kebanyakan manusia tidak lagi mengingat Islam sebagai inspirasi yang membuat umatnya tegak di hadapan umat lain, namun kaum muslim dikenal sebagai umat pesakitan, terpuruk dalam berbagai bidang kehidupan. Bahkan kaum muslim lupa akan jati diri mereka. Pasti ada sesuatu yang diterapkan di masa lalu yang tidak diterapkan di masa kini.

Tujuan penulisan buku Beyond The Inspiration dapat diketahui pada muqaddimahnya yaitu pada kalimat maka satu-satunya pilihan saya, 
adalah menunaikan kewajiban dakwah mengembalikan kehidupan Islam ke tengah-tengah masyarakat (Siauw, 2014c: i).

\section{Simpulan}

Setelah melakukan pembahasan dan menganalisis dapat peneliti simpulkan nilai-nilai edukatif dalam karya Felix Y. Siauw adalah sebagai berikut: Nilai-nilai individual: visioner, motivasi, keseriusan, sabar, rajin, memaafkan, hijrah, mudah beradaptasi, tabayyun, kepemimpinan, ketangkasan, mempelajari sebab-sebab kemenangan, simpati, waspada, tidak terburu-buru, rasional, meluruskan niat, adil, optimis, amanah, tawadhu', jujur, husnudzan, rindu pada kebaikan, kecerdasan emosional, keberanian, tawakal, tegas, dan ketulusan. Nilai-nilai sosial: Kesetaraan gender dalam Islam, adab berpakaian, jihad, kekompakan, pendidikan prenatal, menjunjung hak asasi manusia, birrul walidain, tata tertib, etika pergaulan dalam Islam, etika terhadap musuh, keteladanan, toleransi, serta adab makan dan minum. Nilai-nilai praktis: langkah membentuk habits. Nilai-nilai dakwah: melembaga, menyampaikan kebaikan, dan kewajiban.

\section{Daftar Pustaka}

Hidayatullah, M Furqon. 2010. Guru Sejati: Membangun Insan Berkarakter Kuat dan Cerdas. Surakarta: Yuma Pustaka.

Kaswardi, EM, K. 1993. Pendidikan Nilai Memasuki Tahun 2000. Jakarta: PT Gasindo.

Muhaimin., Abdul Mujib. 1993. Pemikiran Pendidikan Islam: Kajian Filosofis dan Kerangka Dasar Operasionalnya. Bandung: PT Trigenda Karya. 
Siauw, Felix Y. 2013. Udah Putusin Aja. Bandung: Mizania.

Siauw, Felix Y. 2014a. Beyond the Inspiration. Jakarta: AlFatih Press.

Siauw, Felix Y. 2014b. How to Master Your Habits. Jakarta: AlFatih Press.

Siauw, Felix Y. 2015b. Yuk Berhijab. Jakarta AlFatih Press. 
Mudarrisa: Jurnal Kajian Pendidikan Islam, Vol. 7, No.1, Juni 2015: 1-28 